\title{
Biocontrol Characteristics of Bacillus Species in Suppressing Stem Rot of Grafted Cactus Caused by Bipolaris cactivora
}

\author{
Sooil Bae, Sang Gyu Kim and Young Ho Kim* \\ Department of Agricultural Biotechnology, Seoul National University, Seoul 151-921, Korea \\ (Received on July 26, 2012; Revised on October 10, 2012; Accepted on October 10, 2012)
}

One of the most important limiting factors for the production of the grafted cactus in Korea is the qualitative and quantitative yield loss derived from stem rots especially caused by Bipolaris cactivora. This study is aimed to develop microbial control agents useful for the control of the bipolaris stem rot. Two bacteria (GA1-23 and GA4-4) selected out of 943 microbial isolates because of their strong antibiotic activity against $B$. cactivora were identified as Bacillus subtilis and B. amyloliquefaciens, respectively, by the cultural characteristics, Biolog program and 16S rRNA sequencing analyses. Both bacterial isolates significantly inhibited the conidial germination and mycelial growth of the pathogen with no significant difference between the two, of which the inhibitory efficacies varied depending on the cultural conditions such as temperature, nutritional compositions and concentrations. Light and electron microscopy of the pathogen treated with the bacterial isolates showed the inhibition of spore germination with initial malformation of germ tubes and later formation of circlelike vesicles with no hyphal growth and hyphal disruption sometimes accompanied by hyphal swellings and shrinkages adjacent to the bacteria, suggesting their antibiotic mode of antagonistic activity. Control efficacy of $B$. subtilis GA1-23 and B. amyloliquefaciens GA4-4 on the cactus stem rot were not as high as but comparable to that of fungicide difenoconazole when they were treated simultaneously at the time of pathogen inoculation. All of these results suggest the two bacterial isolates have a good potential to be developed as biocontrol agents for the bipolaris stem rot of the grafted cactus.

Keywords : Bacillus species, biocontrol, Bipolaris cactivora, bipolaris stem rot, grafted cactus

The Cactaceae are mostly spiny succulents with photosynthetic stems comprising 200 genera and more than 2,000 species (Min et al., 2006). More than 300 species of cacti are cultivated as ornamentals (Anderson, 2001). The grafted

\footnotetext{
*Corresponding author.

Phone) +82-2-880-4675, FAX) +82-2-873-2317

E-mail) yhokim@snu.ac.kr
}

cactus composed of two cactus species, a photosynthetic stock and an esthetically-valued scion, is an ornamental plant, which is produced most abundantly in Korea, comprising about $70 \%$ of the world trading market (Song et al., 2009a, 2009b). The cultivation area of cacti in Korea was 38.3 ha in 1990, increased to 50.2 ha in 2000, and reached 73.7 ha, with a production of 29 million plants in 2004 (Jeong et al., 2004).

The grafted cactus is cultivated in a greenhouse with warm temperature $\left(15-34^{\circ} \mathrm{C}\right)$ and humid conditions during all growing seasons, and thus, a variety of diseases caused by fungi, bacteria and viruses are found in the cactus farms (Chang et al., 1998; Chase, 1982; Choi et al., 2010b; Durbin et al., 1955; Hyun et al., 2001; Kim et al., 2000a; Kim et al., 2000b; Kim et al., 2007; Liou et al., 2001). Especially, bipolaris stem rot caused by $B$. cactivora is one of the most important diseases in cactus farms, sometimes devastating a large area of the cactus plantations, so that it should be controlled properly to secure the production of quality grafted cactus.

Stem rots caused by fungal pathogens including $B$. cactivora are commonly controlled by chemical fungicides. However, the fungicides are toxic to be harmful to humans and animals, sometimes adversely affecting on the non-target beneficial organisms and causing environmental pollutions. Hence, it is necessary to develop other control measures using safe and eco-friendly biocontrol agents that can substitute for synthetic fungicides for the practical control of the diseases in farms.

In recent years, biotic or abiotic factors such as siderophores, antibiotics, volatile compounds, HCN, enzymes, phytohormones, neem oil, and commercial xanthan gum have been used as biological control agents (Castro and Bach, 2004; Solemani et al., 2005). However, biological control using antagonistic microorganisms is one of the important alternatives to the fungicidal use and provides an ecology-based approach for the integrated pest management in sustainable agriculture in crop production systems (Lee et al., 2006). Previous studies on biocontrol agents include the effects of foliar and root applications of Lysobacter enzymogenes strain $\mathrm{C} 3$ in the suppression of conidial 
germination and leaf spot development after pathogen inoculation (Kilic-Ekici and Yuen, 2004). Fluorescent Pseudomonas and Bacillus spp. not only reduce the incidence and severity of the disease, comparing with the control, but also influence positively on the growth and yield of wheat cultivars (Solemani et al., 2005). Therefore, in this study, experiments were conducted to control bipolaris stem rot caused by B. cactivora using antifungal microorganisms especially Bacillus species. Optimal conditions for their treatment were evaluated by in vitro and in vivo experimentations. Also biocontrol mechanisms of the Bacillus species were examined by light and scanning electron microscopy (SEM).

\section{Materials and Methods}

Pathogen and in vitro screening of antifungal bacteria against B. cactivora. An isolate of $B$. cactivora, $\mathrm{CC} 1-5$ that has been used in the previous study (Choi et al., 2010a) was also used for this study. A total of 943 microbial isolates were collected during the survey of effective microorganisms used for the biocontrol of cactus stem rot caused by $B$. cactivora for two years of 2009 and 2010. These isolates were screened for antifungal activity against $B$. cactivora. For this, mycelial discs (7 $\mathrm{mm}$ in diameter) of $B$. cactivora CC1-5 cultured on potato-dextrose agar (PDA) for 7 days were placed in the center of PDA and spotted with $10 \mu \mathrm{l}$ of bacterial suspensions grown in brain-heart infusion (BHI) broth at $28^{\circ} \mathrm{C}$ for $48 \mathrm{~h}$ with shaking at 200 $\mathrm{rpm}$ around the mycelial discs in a distance of $3 \mathrm{~cm}$. After incubation for 7 days, the inhibitory activity was measured for each bacterial isolate as the length of the mycelial growth of $B$. cactivora compared to the untreated control. Three replications were used for each treatment.

Identification of antifungal bacteria. The two bacterial isolates GA1-23 and GA4-4 with high antifungal activity against $B$. cactivora were selected for further biocontrol study. These isolates were identified based on cultural and physiological characters, and analysis with the Biolog program. To confirm the bacterial identities, 16S rRNA gene sequences of the bacterial isolates were analyzed using 27mF (5'-AGAGTTTGTTTGATCMTGGCTCAG-3') and 1492mR (5'-GGYTACCTTGTTACGACTT-3') primers (Brosius et al., 1978; Weisburg et al., 1991) after 16S rRNA genes were amplified by PCR.

Antifungal activities of the bacterial isolates in suppressing the spore germination of $B$. cactivora at different cultural conditions and inoculum concentrations. The germination of $B$. cactivora spores was examined in liquid and solid media treated with the bacterial isolates. For liquid medium, $1 \mathrm{ml}$ of $B$. cactivora conidial suspension $\left(1.0 \times 10^{7}\right.$ conidia $\left./ \mathrm{ml}\right)$ grown on V8 juice agar for 10 days was mixed with $1 \mathrm{ml}$ of each bacterial suspension $\left(1.0 \times 10^{8}\right.$ $\mathrm{CFU} / \mathrm{ml}$ ) that was grown on BHI broth at $28^{\circ} \mathrm{C}$ for $48 \mathrm{~h}$ with shaking at $200 \mathrm{rpm}$. BHI broth was used as control. Two $\mathrm{ml}$ of these mixtures were suspended in $250 \mathrm{ml}$ of potato-dextrose broth (PDB) (CONDA, Madrid, Spain) and incubated $25^{\circ} \mathrm{C}$ for $9 \mathrm{~h}$ with shaking at $200 \mathrm{rpm}$. The spore germination in $1 \mathrm{ml}$ of each suspension was examined under a compound light microscope at intervals of $3 \mathrm{~h}$ after inoculation with 5 replications based on the spore germination to be determined by the germ tube length 1.5 times longer than the spore length.

For solid media, $500 \mu \mathrm{l}$ conidial suspension of B. cactivora $\left(1.0 \times 10^{7}\right.$ conidia $\left./ \mathrm{ml}\right)$ grown on V8 juice agar for 10 days was mixed with $500 \mu \mathrm{l}$ of each bacterial suspension $\left(1.0 \times 10^{8} \mathrm{cfu} / \mathrm{ml}\right)$ that was grown on BHI broth at $28^{\circ} \mathrm{C}$ for $48 \mathrm{~h}$ with shaking at $200 \mathrm{rpm}$. BHI was used as the untreated control. Ten $\mu \mathrm{l}$ of mixtures were spotted on water agar (WA) (as for non-nutritional medium) and PDA (as for nutritional medium), respectively and incubated at $25^{\circ} \mathrm{C}$ in a growth chamber for $9 \mathrm{~h}$. The surface of each medium was examined at intervals of $3 \mathrm{~h}$ after inoculation to visualize the spore germination rates with time on a microscopic view at $400 \times$ magnification with 9 replications based on the germ tube length over $1.5 \times$ of the spore length.

For evaluation of inhibitory activity of the antifungal bacteria on spore germination of B. cactivora at different inoculum concentrations of the bacterial isolates, the fungal conidia were harvested by scraping the surface of 10-dayold fungal cultures grown on V8 juice agar with a spreader and suspended in sterile distilled water followed by filtration through two layers of Mira cloth. Conidial concentrations were adjusted to $3.0 \times 10^{6} \mathrm{conidia} / \mathrm{ml}$ using a hemacytometer. The conidial suspension of $B$. cactivora $(1 \mathrm{ml})$ was mixed in 11 of melted PDA, which was poured to an amount of $15 \mathrm{ml}$ in a petri dish. Sixty $\mu$ l of each bacterial suspension $\left(1.0 \times 10^{8} \mathrm{cfu} / \mathrm{ml}\right)$ grown in BHI broth at $28^{\circ} \mathrm{C}$ for 2 days with shaking at $200 \mathrm{rpm}$ was spotted on each of sterile paper discs 8-mm in diameter (ADVANTEC, Japan). The paper discs were placed on the surface of PDA amended with the conidial suspension. After $48 \mathrm{~h}$ of incubation, the size of an inhibition zone around each paper disc was examined.

Antifungal activities of the bacterial isolates in suppressing the mycelial growth of $B$. cactivora at different cultural conditions. The two bacterial isolates were tested for inhibitory activity against the mycelial growth of $B$. cactivora at different temperature and nutrient conditions. For this, mycelial discs of $7 \mathrm{~mm}$ in diameter were cut from B. cactivora cultures grown on PDA at $25^{\circ} \mathrm{C}$ for 7 days and 
placed in the center of $15 \mathrm{ml}$ PDA in a Petri dish, at $3 \mathrm{~cm}$ apart from which were spotted with $10 \mu$ of bacterial suspensions that were grown in BHI broth at $28^{\circ} \mathrm{C}$ for 2 days with shaking at $200 \mathrm{rpm}$. These plates were incubated at different temperatures of $18,21,25$ and $28^{\circ} \mathrm{C}$ for examining the effect of incubation temperature on the antifungal activity of the bacterial isolates. For nutrient concentrations in cultural medium, the mycelial discs were placed in the center of WA with different PDB concentrations of 0,25 , 50,75 and $100 \%$ relative to the standard PDB concentration as $100 \%$, and were spotted at $3 \mathrm{~cm}$ apart from the pathogen discs with $10 \mu \mathrm{l}$ of bacterial suspensions. For nutritional compositions of cultural media, the mycelial discs were placed in six different media including PDA, nutrient agar (NA), brain-heart infusion (BHI) agar, Luria-Bertani agar (LBA), King's B agar (KBA), and tryptic soybean agar (TSA), and were spotted at $3 \mathrm{~cm}$ apart from the mycelial discs of B. cactivora with $10 \mu \mathrm{l}$ of bacterial suspensions. After incubation for 7 days at $25^{\circ} \mathrm{C}$, the inhibitory activity was measured for each bacterial isolate as the length of the mycelial growth of B. cactivora relative to the untreated control.

Mechanism for antifungal activity of the bacterial isolates in suppressing spore germination of $B$. cactivora. The antifungal mechanism of the bacterial isolates for the suppression of spore germination was examined by light microscopy. For light microscopy, $1 \mathrm{ml}$ of $B$. cactivora conidial suspension $\left(1.0 \times 10^{7}\right.$ conidia/ml $)$ grown on $\mathrm{V} 8$ juice agar for 10 days was mixed with $1 \mathrm{ml}$ of each bacterial suspension $\left(1.0 \times 10^{8} \mathrm{cfu} / \mathrm{ml}\right)$ grown on BHI broth at $28^{\circ} \mathrm{C}$ for $48 \mathrm{~h}$ with shaking at $200 \mathrm{rpm}$. BHI broth was used as control. These mixtures were incubated at $25^{\circ} \mathrm{C}$ for 10 days with shaking at $200 \mathrm{rpm}$ and spore germination was observed at $6 \mathrm{~h}$ and 10 days after treatment under a light microscope as initial and later influences of the bacterial isolates against the pathogen, respectively.

Mechanism for antifungal activity of the bacterial isolates in suppressing mycelial growth of $B$. cactivora. Scanning electron microscopy (SEM) was used for examining mechanism of antifungal activity of the bacterial isolates against $B$. cactivora. For SEM, B. cactivora grown on PDA for 7 days was mixed with two bacterial isolates grown in BHI broth for 2 days with shaking at $200 \mathrm{rpm}$. After $24 \mathrm{~h}$ of incubation, mycelial plugs of $B$. cactivora were fixed with Karnovsky's fixative in $2 \%$ paraformaldehyde and $2 \%$ glutaraldehyde in $0.05 \mathrm{M}$ cacodylate buffer at pH 7.2 (Karnovsky, 1965) at $4^{\circ} \mathrm{C}$. After $12 \mathrm{~h}$, the fixed specimens were washed three times with $0.05 \mathrm{M}$ cacodylate buffer for $15 \mathrm{~min}$ each. The specimens were post-fixed with $2 \% \mathrm{OsO}_{4}$ in $0.1 \mathrm{M}$ cacodylate buffer $(\mathrm{pH}$ 7.2 ) at $4^{\circ} \mathrm{C}$ for $4 \mathrm{~h}$. The specimens were washed again with distilled water briefly three times. Then the specimens were dehydrated in an ethanol series of 30, 50, 70, 80 and $90 \%$ for 10 min each, and finally in $100 \%$ ethanol three times for 10 min each. Then the specimens were transited with $100 \%$ isoamyl acetate at room temperature two times each for 10 $\mathrm{min}$. The specimens were subjected to critical point drying, after which they were coated with gold on a Sputter Coater (JFC-1110E, JEOL, Tokyo, Japan). The specimens were observed under a scanning electron microscope (JSM$5410 \mathrm{LV}$, JEOL, Japan) at an acceleration voltage of $20 \mathrm{kV}$.

Phytotoxicity and in vivo biocontrol activities of the bacterial isolates against the stem rot caused by $B$. cactivora. Inoculation of the pathogen to the cactus plant followed the method described in a previous study (Choi et al., 2010a). Three-month-old grafted cacti composed of stock cactus (Hylocereus trigonus $<9 \mathrm{~cm}$ in length $>$ ) and scion cactus (Gymnocalicium mianovichii $<3 \mathrm{~cm}$ in diameter $>$ ) cultivated in a cactus field were used in this experiment. B. cactivora $\mathrm{CC} 1-5$ was cultured on $\mathrm{V} 8$ juice agar $25^{\circ} \mathrm{C}$ for 10 days. Conidia were harvested by scraping the surface of the fungal cultures with a spreader and suspended in sterile distilled water followed by filtration through two layers of Mira cloth. Conidial concentration was adjusted to $1.0 \times 10^{6}$ conidia/ml using a hemacytometer. And then, $1 \%$ of carborundum \# 400 (Hanawa Chemical Pure, Japan) was added to the conidial suspension for wounding plant surfaces at the spraying time of conidial suspension (Kim et al., 2008). The bacterial isolates were cultured in BHI broth at $28^{\circ} \mathrm{C}$ for $48 \mathrm{~h}$ with shaking at 200 $\mathrm{rpm}$ and adjusted to $1.0 \times 10^{8} \mathrm{cfu} / \mathrm{ml}$. Cactus plants were treated with $5 \mathrm{ml}$ of the bacterial suspension at the same time as (as simultaneous treatment), at 2 days before (as pretreatment) or at 2 days after (as post-treatment) inoculation with $B$. cactivora $\mathrm{CC} 1-5$ by spraying $3 \mathrm{ml}$ of conidial suspension $\left(1.0 \times 10^{6}\right.$ conidia $\left./ \mathrm{ml}\right)$ on each scion cactus stem with 5 sites pin-prick wounded ( $5 \mathrm{~mm}$ in depth). Sterile BHI broth served as control. The inoculated and treated cactus plants were placed on three layers of filter paper moistened with $100 \mathrm{ml}$ of sterilized distilled water in a plastic box $(270 \mathrm{~mm} \times 190 \mathrm{~mm})($ LOCK \& LOCK, Korea) and incubated at $25^{\circ} \mathrm{C}$ and relative humidity (RH) of $80 \%$ for $24 \mathrm{~h}$. Then all cactus plants treated were incubated at $25^{\circ} \mathrm{C}$ under 12-h photoperiod in an incubation chamber for 4 weeks. Rot symptom development was examined 4 weeks after inoculation and disease severity was determined by the disease index of 6 scaling; $0=$ no symptom, $1=$ initial small spot, $2=30 \%$ rotten, $3=60 \%$ rotten, $4=90 \%$ rotten, $5=$ the whole scion and stock rotten (Choi et al., 2010a). 


\section{Results}

In vitro screening of antifungal bacteria against $B$. cactivora. A total of 943 microbial isolates were obtained from 40 soil samples of mountains, crop fields and riversides, which included mostly bacteria and several Actinomycetes. These isolates were tested for their antifungal activity against $B$. cactivora, and 4 bacterial isolates GA123, GA4-4, WM7-12 and GC3-7 showed a significant inhibitory activity of over $60 \%$ inhibition rates for the mycelial growth of $B$. cactivora (Table 1, Fig. 1). Among these antagonistic bacteria, GA1-23 and GA4-4 were only used for further studies on the biological control of $B$. cactivora because the other two bacteria showed a poor growth status on several agar media including PDA as noticed in Fig. 1, one of which also exhibited phytotoxicity to the grafted cactus in the further studies (data not shown).

Identification of antifungal bacteria. The colony characteristics of two bacterial isolates GA1-23 and GA4-4 obtained from Mt. Gwanak were cream-colored, flat (GA123 ) and raised (GA4-4) with undulate margins on BHI agar, rod shaped, ca. $1.0 \mu \mathrm{m}$ (diameter) $\times 2.0 \mu \mathrm{m}$ (length), with several peritrichous flagella (Fig. 2). They were all Grampositive, endospore-forming bacteria (data not shown). The carbon source assimilation of the bacterial isolates examined with the Biolog GN test kit (Biolog Inc., Hayward, Co., CA) showed maximum similarities with $99.1 \%$ identity to

Table 1. Effect of bacterial treatments on the inhibition of mycelial growth of Bipolaris cactivora after 7 days of dual culture at $25^{\circ} \mathrm{C}$

\begin{tabular}{ccc}
\hline \hline Treatment & Mycelial growth $(\mathrm{mm})$ & Inhibition rate $(\%)^{\mathrm{a}}$ \\
\hline Control & $29.3 \pm 2.3 \mathrm{X}^{\mathrm{b}}$ & - \\
GA1-23 & $9.8 \pm 1.7 \mathrm{Y}$ & 66.6 \\
GA4-4 & $9.4 \pm 1.6 \mathrm{Y}$ & 67.9 \\
WM7-12 & $10.3 \pm 2.0 \mathrm{Y}$ & 64.8 \\
GA3-7 & $9.8 \pm 1.1 \mathrm{Y}$ & 66.6 \\
\hline
\end{tabular}

${ }^{\mathrm{a}}$ Inhibition rate $(\%)=\{$ (mycelial growth of control - mycelial growth of bacterial treatment $) /$ mycelial growth of control $\} \times 100$

${ }^{b}$ Means followed by the same letter are not significantly different at $P=0.01$ by least significant difference (LSD) test.

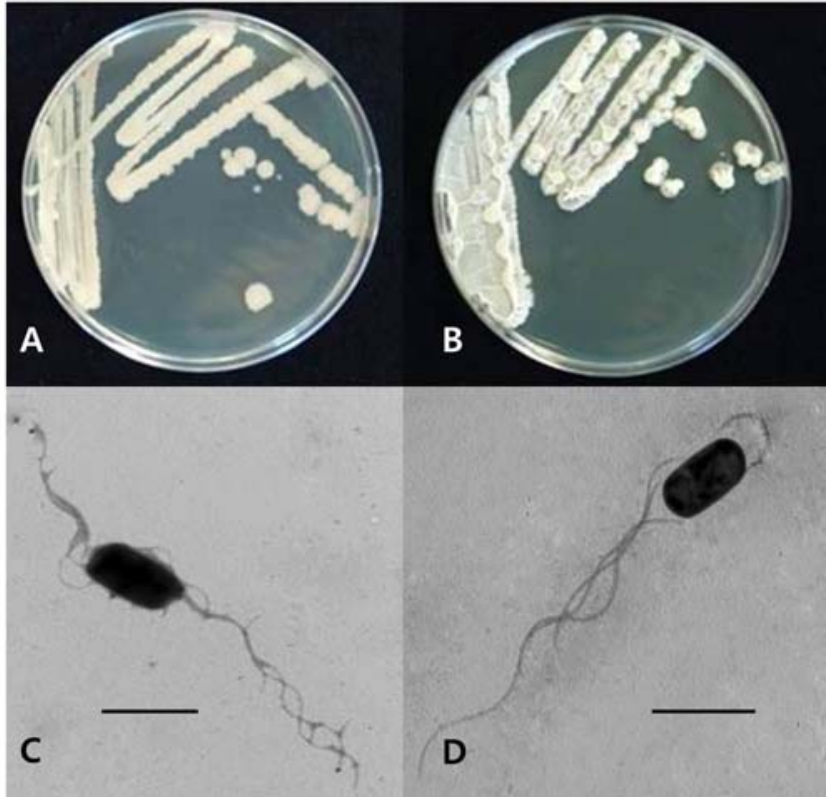

Fig. 2. Cultural and morphological characteristics of bacterial isolates GA1-23 (A, C) and GA4-4 (B, D), showing creamcolored, flat (A) and raised (B) with undulate margins on $\mathrm{BHI}$ agar, rod shaped, ca. 1.0 (diameter) $\times 2.0 \mu \mathrm{m}$ (length), with several peritrichous flagella (C, D). Bars $=1.0 \mu \mathrm{m}$.

Bacillus subtilis and B. amyloliquefaciens for GA1-23 (utilizing 25 carbon sources including sorbitol, inuline and D-turanose but not 24 carbon sources including erythritol, D-xylose and lactose) and with $94.7 \%$ identity to $B$. subtilis and B. amyloliquefaciens for GA4-4 (utilizing 25 carbon sources including sorbitol, D-xylose and lactose but not 24 carbon sources including erythritol, inuline and D-turanose), respectively (data not shown). Analysis of 16S rRNA gene sequences for isolate GA1-23 showed the highest homo$\operatorname{logy}$ of $99 \%$, with $\mathrm{E}$ value of 0.0 , to several B. subtilis strains such as GenBank accession numbers of GQ480495.1, AY825035.1, HQ678655.1, GU322372.1, HM631974.1 and HQ647257.1, and for GA4-4, the highest homology of $99 \%$, with E value of 0.0 , to several B. amyloliquefaciens strains such as GenBank accession numbers of HQ843837.1, HQ853018.1, HQ853016.1 and HQ831424.1. Based on above physiological and molecular genetic analyses, the two bacterial isolates AC23-1 and AC4-4 were identified as

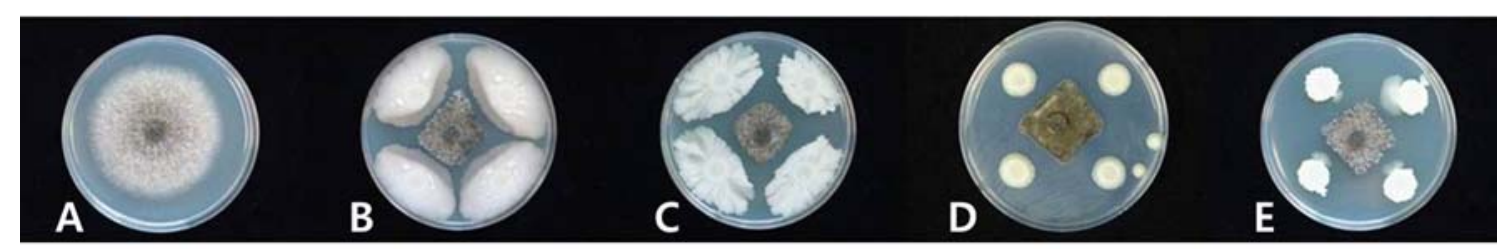

Fig. 1. Effect of bacterial treatments on the inhibition of mycelial growth of Bipolaris cactivora after 7 days of dual culture at $25^{\circ} \mathrm{C}$. A: Untreated control, B: GA1-23, C: GA4-4, D: WM7-12, E: GA3-7. 


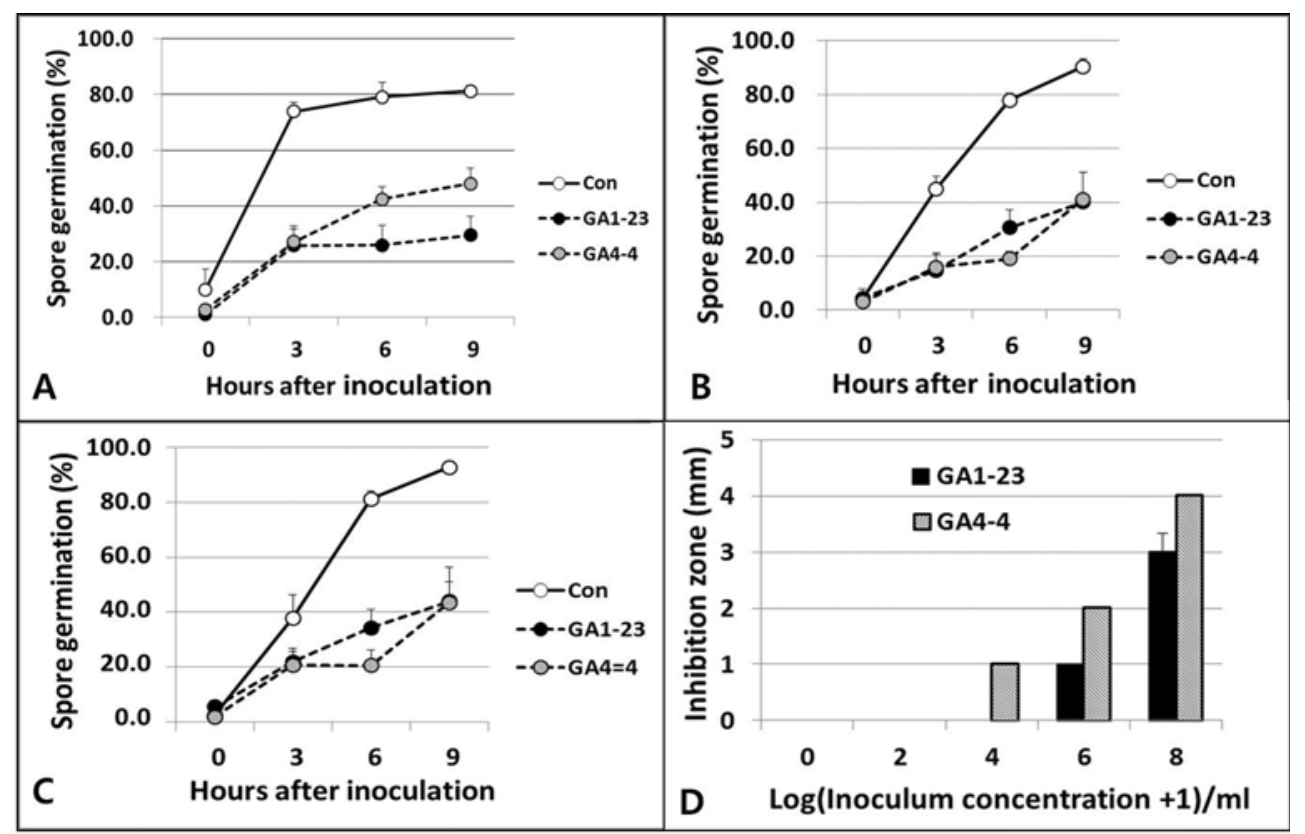

Fig. 3. Effects of bacterial isolates GA1-23 and GA4-4 on the conidial (spore) germination of Bipolaris cactivora in liquid medium (PDB) (A), on solid medium with (PDA) (B) and without nutrients (WA) (C), and on the nutritional solid medium with different inoculum concentrations (D). Marks (bars) and vertical lines are averages and standard deviations of three replications, respectively.

B. subtilis and B. amyloliquefaciens, respectively.

Antifungal activities of bacterial isolates in suppressing the conidial germination of $B$. cactivora at different cultural conditions and inoculum concentrations. The germination of B. cactivora spores was examined in liquid and solid cultural media with and without amendment of nutrients. In a liquid medium, PDB, the spore germination was significantly inhibited in the medium treated with the bacterial isolates, more by B. subtilis AG1-23 than B. amyloliquefaciens AG4-4, compared to the untreated control medium (Fig. 3A). The spore germination was also inhibited significantly on solid media treated with the bacterial isolates compared to the control media; however, it was somewhat (with no significance) more by AG4-4 than by AG1-23, regardless of nutritional amendment (Fig. 3B, C). When the spore germination was examined by the formation of the clear inhibition zones around bacterial spots on BHI agar, the inhibition zone size increased proportionally with the inoculum concentrations and significantly more by the treatment of B. amyloliquefaciens AG4-4 than B. subtilis AG1-23 (Fig. 3D).

Antifungal activities of the bacterial isolates in suppressing the mycelial growth of $B$. cactivora at different cultural conditions. The two bacterial isolates $B$. subtilis

Table 2. Effect of temperature on the inhibitory activity of bacterial isolates against the mycelial growth of Bipolaris cactivora

\begin{tabular}{cccc}
\hline \hline & \multicolumn{3}{c}{ Mycelial growth $(\mathrm{mm})(\text { Inhibition rate, \% })^{\mathrm{a}}$} \\
\cline { 2 - 4 } Temp. $\left({ }^{\circ} \mathrm{C}\right)$ & Treatments & GA4-4 \\
\cline { 2 - 4 } & Control & GA1-23 & $8.6 \pm 1.2(63.3) \mathrm{X}(\mathrm{Z})$ \\
18 & $23.3 \pm 0.9(0.0) \mathrm{W}^{\mathrm{b}}(\mathrm{X})^{\mathrm{c}}$ & $10.2 \pm 1.3(56.2) \mathrm{W}(\mathrm{Y})$ & $8.8 \pm 1.0(67.2) \mathrm{XY}(\mathrm{Y})$ \\
21 & $26.7 \pm 0.7(0.0) \mathrm{X}(\mathrm{X})$ & $9.8 \pm 1.5(63.5) \mathrm{X}(\mathrm{Y})$ & $10.4 \pm 1.6(73.6) \mathrm{Z}(\mathrm{Y})$ \\
25 & $39.6 \pm 1.4(0.0) \mathrm{Y}(\mathrm{X})$ & $10.2 \pm 1.9(74.2) \mathrm{Z}(\mathrm{Y})$ & $9.0 \pm 1.6(70.8) \mathrm{YZ}(\mathrm{Y})$ \\
28 & $30.8 \pm 1.7(0.0) \mathrm{Z}(\mathrm{X})$ & $9.7 \pm 1.0(68.6) \mathrm{Y}(\mathrm{Y})$ & \\
\hline
\end{tabular}

${ }^{a}$ Inhibition rate $(\%)=\{($ mycelial growth of control - mycelial growth of bacterial treatment at the same temperature $) /$ mycelial growth of control $\}$ $\times 100$

${ }^{b}$ Means of mycelial growths in control and inhibition rates of treatments followed by the same letters in a column are not significantly different at $P=0.01$ by least significant difference (LSD) test.

${ }^{\mathrm{c}}$ Means of inhibition rates followed by the same letter in a row are not significantly different at $P=0.01$ by least significant difference (LSD) test. 
Table 3. Effect of nutrient concentrations on the inhibitory activity of bacterial isolates against the mycelial growth of Bipolaris cactivora

\begin{tabular}{cccc}
\hline \hline & \multicolumn{3}{c}{ Mycelial growth (mm) (Inhibition rate, \%) $^{\mathrm{b}}$} \\
\cline { 2 - 4 } Nutrient conc. $(\%)^{\mathrm{a}}$ & Treatments & GA4-4 \\
\cline { 2 - 4 } & Control & GA1-23 & $10.5 \pm 1.4(54.7) \mathrm{X}(\mathrm{Z})$ \\
\cline { 2 - 4 } & $23.2 \pm 0.8(0.0) \mathrm{W}^{\mathrm{c}}(\mathrm{X})^{\mathrm{d}}$ & $13.0 \pm 1.7(43.9) \mathrm{X}(\mathrm{Y})$ & $11.3 \pm 0.8(56.1) \mathrm{X}(\mathrm{Y})$ \\
25 & $25.8 \pm 2.8(0.0) \mathrm{X}(\mathrm{X})$ & $11.5 \pm 2.7(55.5) \mathrm{Y}(\mathrm{Y})$ & $10.2 \pm 1.7(71.1) \mathrm{Y}(\mathrm{Y})$ \\
50 & $35.0 \pm 0.6(0.0) \mathrm{Y}(\mathrm{X})$ & $11.3 \pm 1.0(67.6) \mathrm{Z}(\mathrm{Y})$ & $10.3 \pm 1.5(73.8) \mathrm{Y}(\mathrm{Y})$ \\
75 & $39.5 \pm 1.4(0.0) \mathrm{Z}(\mathrm{X})$ & $11.0 \pm 1.7(72.2) \mathrm{Z}(\mathrm{Y})$ & $10.0 \pm 2.0(75.2) \mathrm{Y}(\mathrm{Y})$ \\
\hline
\end{tabular}

${ }^{a}$ Nutrient concentration (\%): concentration of potato-dextrose broth in water agar relative to the standard concentration of $\mathrm{PD}_{\text {broth }}\left(26.5 \mathrm{gL}^{-1}\right)$

${ }^{\mathrm{b}}$ Inhibition rate $(\%)=\{$ (mycelial growth of control - mycelial growth of bacterial treatment at the same nutrient concentration)/mycelial growth of control\} $\times 100$

${ }^{\mathrm{c}}$ Means of mycelial growths in control and inhibition rates of treatments followed by the same letters in a column are not significantly different at $P=0.01$ by least significant difference (LSD) test.

${ }^{\mathrm{d}}$ Means of inhibition rates followed by the same letters in a row are not significantly different at $P=0.01$ by least significant difference (LSD) test.

Table 4. Effect of nutrient compositions (medium types) on the inhibitory activity of bacterial isolates against the mycelial growth of Bipolaris cactivora

\begin{tabular}{lccc}
\hline \hline & \multicolumn{3}{c}{${\text { Mycelial growth }(\mathrm{mm}) \text { (Inhibition rate, \% })^{\mathrm{a}}}^{\text {Treatments }}$} \\
\cline { 2 - 4 } & Control & GA1-23 & GA4-4 \\
\cline { 2 - 4 } & $32.3 \pm 1.7(0.0) \mathrm{W}^{\mathrm{b}}(\mathrm{X})^{\mathrm{c}}$ & $7.4 \pm 1.7(77.0) \mathrm{W}(\mathrm{Y})$ & $7.4 \pm 1.1(77.0) \mathrm{X}(\mathrm{Y})$ \\
PDA & $19.6 \pm 2.4(0.0) \mathrm{Z}(\mathrm{X})$ & $6.2 \pm 2.7(68.2) \mathrm{X}(\mathrm{Y})$ & $6.1 \pm 1.3(68.8) \mathrm{Y}(\mathrm{Y})$ \\
NA & $28.6 \pm 1.2(0.0) \mathrm{X}(\mathrm{X})$ & $8.1 \pm 1.0(71.6) \mathrm{WX}(\mathrm{Y})$ & $7.8 \pm 1.0(72.8) \mathrm{XY}(\mathrm{Y})$ \\
BHIA & $18.2 \pm 1.3(0.0) \mathrm{Z}(\mathrm{X})$ & $9.3 \pm 1.7(48.62) \mathrm{Z}(\mathrm{Y})$ & $7.0 \pm 0.6(61.5) \mathrm{Z}(\mathrm{Y})$ \\
LBA & $30.3 \pm 1.4(0.0) \mathrm{WX}(\mathrm{X})$ & $7.3 \pm 1.5(75.8) \mathrm{W}(\mathrm{Y})$ & $7.0 \pm 1.3(76.9) \mathrm{X}(\mathrm{Y})$ \\
KBA & $25.3 \pm 4.5(0.0) \mathrm{Y}(\mathrm{X})$ & $9.8 \pm 1.5(61.4) \mathrm{Y}(\mathrm{Y})$ & $7.7 \pm 1.5(69.7) \mathrm{Y}(\mathrm{Y})$ \\
TSA & &
\end{tabular}

${ }^{\mathrm{a}}$ Inhibition rate $(\%)=\{$ (mycelial growth of control - mycelial growth of bacterial treatment at the same nutrient concentration)/mycelial growth of control\} $\times 100$

${ }^{\mathrm{b}}$ Means of mycelial growths in control and inhibition rates of treatments followed by the same letters in a column are not significantly different at $P=0.01$ by least significant difference (LSD) test.

Means of inhibition rates followed by the same letters in a row are not significantly different at $P=0.01$ by least significant difference (LSD) test.

GA1-23 and B. amyloliquefaciens GA4-4 were tested for antifungal activity against $B$. cactivora under different temperature and nutrient conditions for their incubation. For incubation temperature, the mycelial growth of the pathogen and the antifungal activities of both bacterial isolates were increased with the temperature increase up to $25^{\circ} \mathrm{C}$, but decreased somewhat at $28^{\circ} \mathrm{C}$ (Table 2). No significant difference in the antifungal activity was noted between two bacterial isolates at all temperature conditions except $18^{\circ} \mathrm{C}$, at which B. subtilis GA1-23 was lower than B. amyloliquefaciens GA4-4 in inhibitory activity against the mycelial growth of the pathogen. The mycelial growth of the pathogen and the antifungal activities of both bacterial isolates were significantly increased with the increase of nutrient concentrations, and no significant difference in the antifungal activity was noted between two bacterial isolates at all nutritional concentrations except for WA with no nutrient, where $B$. subtilis GA1-23 was significantly lower in anti- fungal activity than B. amyloliquefaciens GA4-4 (Table 3). For nutrient conditions related to culture media (nutritional compositions), the mycelial growth of the pathogen was significantly different among cultural media (higher in the order of PDA, KBA, BHIA, TSA, NA and LBA), and the antifungal activity of both isolates was highest in PDA and KBA, followed in turn by BHIA, NA, TSA and LBA (Table 4). However, there was no difference in the antifungal activity between the two isolates on all cultural media except LBA, where B. amyloliquefaciens GA4-4 had stronger antifungal activity than $B$. subtilis GA1-23.

Mechanism for antifungal activity of the bacterial isolates in suppressing spore germination of $B$. cactivora. In light microscopy, the conidia of $B$. cactivora treated with the bacterial isolates at the initial stages (after $6 \mathrm{~h}$ of incubation) germinated as with the non-treated control; however, the bases of germ tubes adjacent to the conidia were swollen 


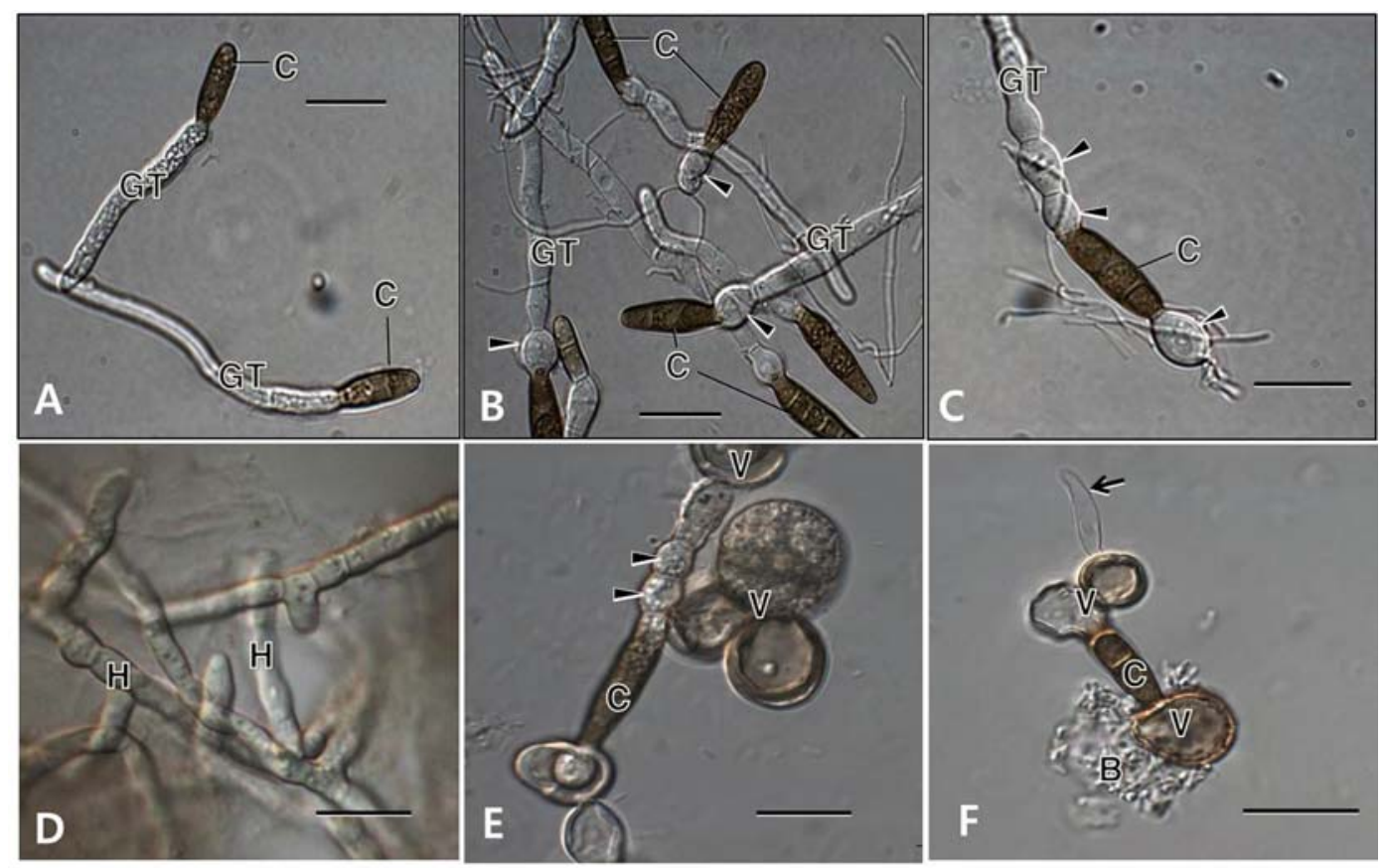

Fig. 4. Light micrographs for conidial germination of Bipolaris cactivora treated with none (A, D), Bacillus subtilis AG1-23 (B, E) and B. amyloliquefaciens AG4-4 (C, F) after $6 \mathrm{~h}(\mathrm{~A}, \mathrm{~B}, \mathrm{C})$ and 10 days (D, E, F) of incubation, showing, the bases of germ tubes (GT) adjacent to the conidia were swollen (arrowheads) with or without the growth of germ tubes, indicating the occurrence of aberrant spore germination (A-C). At 10 days after treatment, extensive interwoven hyphal growth was observed in the untreated control (D), while no hyphae but in (F) numerous large vesicles (V) were formed adjacent to the residual conidia (C), sometimes attached with an empty germ tube (arrow). B: bacterial cells. Bars $=20 \mu \mathrm{m}$.

with or without the growth of germ tubes, indicating the occurrence of aberrant spore germination (Fig. 4A-C). At 10 days after treatment, extensive interwoven hyphal growth was observed in the untreated control (Fig. 4D), while no hyphae but numerous large vesicles probably derived from the initial swellings were formed adjacent to the residual conidia, sometimes attached with an empty germ tube (Fig. 4E, F).
Mechanism for antifungal activity of the bacterial isolates in suppressing mycelial growth of $\boldsymbol{B}$. cactivora. Scanning electron microscopy showed normal-looking fungal hyphae with smooth and intact surfaces in no treatment control (Fig. 5A), while the fungal hyphae treated with $B$. subtilis GA1-23 and B. amyloliquefaciens GA4-4 appeared to be hindered in their intact growths mostly by the concomitant hyphal swellings and shrinkages (Fig. 5B) and physical disruptions (Fig. 5C), respectively. Bacterial


Fig. 5. Scanning electron micrographs of Bipolaris cactivora treated with bacterial isolates at 7 days after treatment, showing fungal hyphae $(\mathrm{H})$ with intact surfaces in no treatment control (A), and abundant bacterial cells $(\mathrm{B})$ and concomitant hyphal swellings (arrowheads) and shrinkages (asterisks), and physical disruptions (arrows) in the treatments of Bacillus subtilis AG23-1 (B) and B. amyloliquefaciens AG4-4 (C), respectively. Bars $=10 \mu \mathrm{m}$. 
Table 5. Effect of bacterial and fungicidal treatments on the inhibition of stem rots of cactus caused by Bipolaris cactivora

\begin{tabular}{|c|c|c|c|c|}
\hline \multirow{3}{*}{ Treatments } & \multicolumn{4}{|c|}{ Disease severity index ${ }^{\mathrm{a}}(\text { Control efficacy, } \%)^{\mathrm{b}}$} \\
\hline & \multicolumn{4}{|c|}{ Application time relative to pathogen inoculation } \\
\hline & No inoculation & $\begin{array}{c}\text { Pretreatment } \\
\text { (Before inoculation) }\end{array}$ & $\begin{array}{c}\text { Simultaneous } \\
\text { treatment }\end{array}$ & $\begin{array}{c}\text { Post-treatment } \\
\text { (After inoculation) }\end{array}$ \\
\hline BHI (Control) & $0.0 \pm 0.0(100.0) X^{c}(X)^{d}$ & $2.0 \pm 0.0(0.0) \mathrm{X}(\mathrm{Y})$ & $2.8 \pm 0.8(0.0) \mathrm{X}(\mathrm{Y})$ & $3.2 \pm 1.6(0.0) \mathrm{X}(\mathrm{Y})$ \\
\hline Difenoconazole & $0.0 \pm 0.0(100.0) \mathrm{X}(\mathrm{X})$ & $0.2 \pm 0.5(90.0) \mathrm{Y}(\mathrm{X})$ & $0.0 \pm 0.0(100.0) \mathrm{Z}(\mathrm{X})$ & $2.6 \pm 1.5(18.8) \mathrm{X}(\mathrm{Y})$ \\
\hline GA1-23 & $0.0 \pm 0.0(100.0) \mathrm{X}(\mathrm{X})$ & $2.4 \pm 1.7(-20.0) \mathrm{X}(\mathrm{Z})$ & $1.0 \pm 0.0(64.3) \mathrm{Y}(\mathrm{XY})$ & $2.8 \pm 1.3(12.5) \mathrm{X}(\mathrm{YZ})$ \\
\hline GA4-4 & $0.0 \pm 0.0(100.0) \mathrm{X}(\mathrm{X})$ & $2.2 \pm 0.8(-10.0) \mathrm{X}(\mathrm{Y})$ & $1.0 \pm 1.0(64.3) \mathrm{Y}(\mathrm{X})$ & $3.8 \pm 1.6(-18.8) \mathrm{X}(\mathrm{Y})$ \\
\hline
\end{tabular}

${ }^{a}$ Disease severity index followed a six-scaling degree of $0=$ no, $1=$ initial small spot, $2=\leq 30 \%$ rotten, $3=\leq 60 \%$ rotten, $4=\leq 90 \%$ rotten, and 5 $=100 \%$ (whole scion and stock) rotten symptoms (Choi et al., 2010).

${ }^{\mathrm{b}}$ Control efficacy $(\%)=\{$ (Disease severity index of control - disease severity of treatment $) /$ disease severity index of control at the same application time $\} \times 100$

${ }^{\circ}$ Means of control efficacy followed by the same letters in a column are not significantly different at $P=0.01$ by least significant difference (LSD) test.

${ }^{\mathrm{d}}$ Means of control efficacy followed by the same letter in a row are not significantly different at $P=0.01$ by least significant difference (LSD) test.

cells were distributed in abundance around the pathogen hyphae treated with the bacterial isolates.

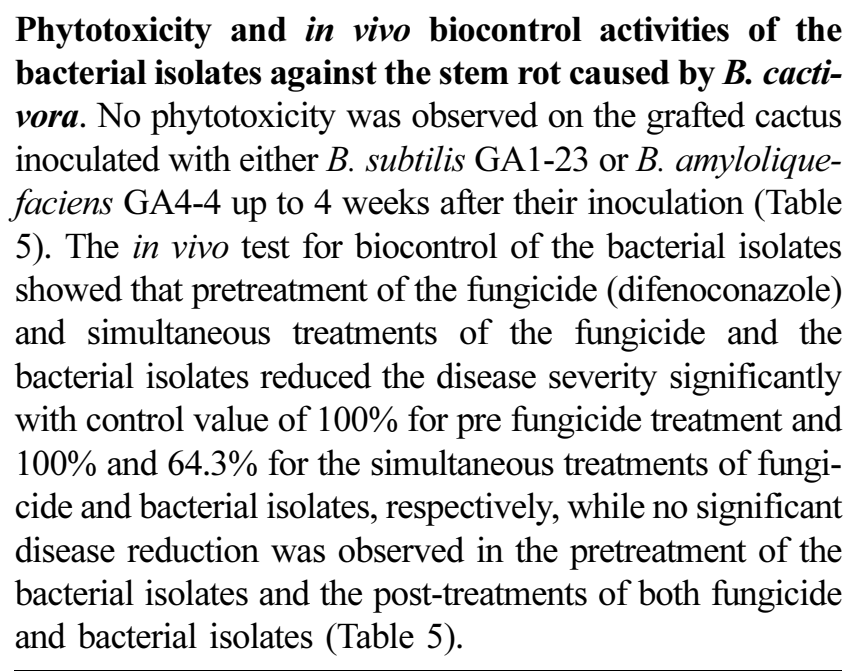

\section{Discussion}

In our study, two antifungal bacteria GA1-23 and GA4-4 finally selected out of 943 microbial isolates obtained from various regions were strongly antagonistic to $B$. cactivora causing the bipolaris stem rot of the grafted cactus. They were identified as B. subtilis GA1-23 and B. amyloliquefaciens GA4-4, respectively, based on cultural and physiological characteristics, Biolog program, and 16S rRNA sequencing analyses. Control efficacy of $B$. subtilis GA1-23 and $B$. amyloliquefaciens GA4-4 on the cactus stem rot were not as high as but comparable to that of fungicide difenoconazole when they were treated simultaneously at the time of pathogen inoculation. However, no significant control efficacies of the stem rot were noted by the bacterial treatments before and especially after the pathogen inoculation for which no significant fungicidal effect was observed as well.

In the infection cycle of the pathogen, spore germination and mycelial growth are involved importantly in the pathogen penetration and invasive growth, which govern the onset and development of the disease, respectively (Agrios, 2005). Our experimental data showed both bacterial isolates inhibited significantly the two processes in the life cycle of $B$. cactivora, including conidial germination and mycelial growth. In comparison of these antagonistic activities against $B$. cactivora, there was no significant difference between the bacterial isolates, regardless of the cultural conditions. For the pathogen mycelial growth, both bacterial isolates showed higher inhibitory efficacies at the incubation conditions of warm temperature (at $25^{\circ} \mathrm{C}$ ), at higher nutrient concentrations, and on the culture media of PDA and KBA. Both bacterial isolates also showed similar inhibitory efficacies and same inhibitory mechanism (swelling of germ tubes) for the conidial germination of the pathogen; however, GA4-4 was more effective on solid media, but GA1-23 in liquid medium than the other bacterial isolate, respectively. Considering that the warm and humid environmental conditions are needed for the cultivation of the grafted cactus, they may exert their full potential for the control of the disease as indicated in vitro experiments in our study. However, the efficacies of the bacterial isolates in the control of the disease may vary depending on environmental conditions and microbial formulations because the microclimatic conditions of plant surfaces vary to determine the actual time period for antagonist-pathogen interactions during the time needed for spore germination and infection of the pathogen (Köhl and Fokkema, 1998). The conidial germination for the pathogen infection may be affected by the changing nutrient levels on the plant surface and leaching of nutrients from the spore by the bacterial activity 
(Blakeman and Brodie, 1976; Brodie and Blakeman, 1976), which may be influenced by the temperature and nutritional types and concentrations on the plant surface as shown in our study.

Bacillus species have characteristics useful for producing commercial microbial agents with a long shelf-life and resistance to environmental stresses because of their ability to form endospores (Chanway, 2002; Kim et al., 2010; Walker et al., 1998). Their antagonistic mode attributes mostly to antibiosis by producing many antagonistic substances (Chanway, 2002; Dijksterrhuis et al., 1999; Haggag, 2007; Haggag and Timmusk, 2008; Helbig, 2001; Khan et al., 2008). In our study, the major antagonistic mode of the bacterial isolates also seems to be antibiosis as their treatments caused destruction and abnormal structural changes of both conidia and hyphae, which may not be derived from the inhibition of the pathogen growth due to the lack of nutritional substances and/or spaces deprived by the competing biocontrol agents. These biocontrol characteristics of Bacillus spp. imply that they may be potential biocontrol candidates effective especially for airborne diseases on the above-ground plant parts, on which harsh environment prevails extensively compared to underground soil environment, providing short time spans for antagonist-pathogen interactions (Köhl and Fokkema, 1998). On the aerial plant surface, the moisture contents are rarely sufficient for the activity of the bacterial isolates in controlling pathogens except for the period of time during the pathogen infection (spore germination) in full moisture conditions. This is probably the main reason that the control efficiency of the bacterial isolates in our study was reliably high only by their simultaneous treatment with the pathogen inoculation, decreasing the possibility for the antagonists to be confronted with the pathogen that was inoculated either before or after their treatment. In this sense, it is required that the biocontrol agents should be formulated properly and/or supplemented with some surfactants for them to be placed and populated on the infection courts (aerial plant surfaces) for the plant pathogen. Nevertheless, the biocontrol efficacy of the bacterial isolates comparable to that of the fungicide in such conditions adverse to their activity suggest that the two bacterial isolates have a good potential to be developed as biocontrol agents effective for the suppression of the bipolaris stem rot of the grafted cactus caused by $B$. cactivora.

\section{References}

Agrios, G. N. 2005. Plant Pathology, 5th ed. Elsevier Academic Press, London, UK. 922 pp.

Anderson, M. 2001. The Cactus Family. Timber Press, Portland, Oregon, US.

Brosius, J., Palmet, M. L., Kennedy, P. J. and Noller, H. F. 1978.
Complete nucleotide sequence of a 16S ribosomal RNA gene from Escherichia coli. Proc. Natl. Acad. Sci. USA 75:48014805.

Blakeman, J. P. and Brodie, I. D. S. 1976. Inhibition of pathogens by epiphytic bacteria on aerial plant surfaces. In: Microbiology of Aerial Plant Surfaces, ed. by C. H. Dickinson and T. F. Preece, pp. 529-551. Academic Press, London, UK.

Brodie, I. D. S. and Blakeman, J. P. 1976. Competition for exogenous substrates in vitro by leaf surface microorganisms and germination of conidia of Botrytis cinerea. Physiol. Plant Pathol. 9: 227-239.

Castro, O. L. and Bach, E. E. 2004. Increased production of $\beta-1,3-$ glucanase and proteins in Bipolaris sorokiniana pathosystem treated using commercial xanthan gum. Plant Physiol. Biochem. 42:165-169.

Chang, M., Hyun, I.-H. and Lee, Y.-H. 1998. Bipolaris stem rot of cactus caused by Bipolaris cactivora (Petrak) Alcorn. Korean J. Plant Pathol. 14:661-663.

Chanway, C. P. 2002. Chapter 15. Plant growth promotion by Bacillus and relatives. In: Applications and systematic of Bacillus and relatives, ed. by R. Berkeley, M. Heyndricks, N. Logan and P. De Vos, pp. 219-235. Blackwell Science, Ltd., Oxford, UK.

Chase, A. R. 1982. Stem rot and shattering of Easter cactus caused by Drechslera cactivora. Plant Dis. 66:602-603.

Choi, M-O., Kim, S. G. and Kim, Y. H. 2010a. Suppression of bipolaris stem rot on cactus by heat-inactivated conidial suspension of Bipolaris cactivora. Plant Pathol. J. 26:231-237.

Choi, M.-O., Kim, S. G., Hyun, I.-H., Kim, J. H., Cho, C.-H., Park, M. S. and Kim, Y. H. 2010b. First report of black spot caused by Alternaria alternata on grafted cactus. Plant Pathol. J. 26:80-82.

Dijksterhuis, J., Sanders, M., Gorris, L. G. M. and Smid, E. J. 1999. Antibiosis plays a role in the context of direct interaction during antagonism of Paenibacillus polymyxa towards Fusarium oxysporum. J. Appl. Microbiol. 86:13-21.

Durbin, R. D., Davis, L. H. and Baker, K. F. 1955. A helminthosporium stem rot of cacti. Phytopathology 45:509-512.

Haggag, W. M. 2007. Colonization of expolysaccharide-producing Paenibacillus polymyxa on peanut roots for enhancing resistance against crown rot disease. Afr. J. Biotechnol. 6: $1568-1577$.

Haggag, W. M. and Timmusk, S. 2008. Colonization of peanut roots by biofilm-forming Paenibacillus polymyxa initiates biocontrol against crown rot disease. J. Appl. Microbiol. 104: 961-969.

Helbig J. 2001. Biological control of Botrytis cinerea Pers. ex Fr. in strawberry by Paenibacillus polymyxa (Isolate 18191). J. Phytopathol. 149:265-273.

Hyun, I.-H., Lee, S.-D., Hwang, B.-C., Ko, K.-I., Chung, H.-S. and Kim, B.-K. 2001. Occurrence of stem rot caused by Bipolaris cactivora on different species of cactus and its pathogenicity. Res. Plant Dis. (in Korean) 7:56-59.

Hyun, I.-H., Lee, S. D., Lee, Y. H. and Heo, N. Y. 1998. Mycological characteristics and pathogenicity of Fusarium oxysporum Schlecht. Emend. Snyd. \& Hans. causing stem rot of cactus. 
Korean J. Plant Pathol. 14:463-466.

Jeong, M. I., Cho, C.-H. and Lee, J.-M. 2004. Production and breeding of cacti for grafting in Korea. Chronica Horticulturae 44:7-10.

Karnovsky, M. J. 1965. A formaldehyde-glutaraldehyde fixative of high osmolarity for use in electron microscopy. J. Cell Biol. 27: 137A.

Khan, Z., Kim, S. G., Jeon, Y. H., Khan, H. U., Son, S. H. and Kim, Y. H. 2008. A plant growth promoting rhizobacterium, Paenibacillus polymyxa strain GBR-1, suppresses root-knot nematode. Bioresour. Technol. 99:3016-3023.

Kilic-Ekici, O. and Yuen, G. Y. 2004. Comparison of strains of Lysobacter enzymogenes and PGPR for induction of resistance against Bipolaris sorokiniana in tall fescue. Biol. Cont. 30:446-455.

Kim, J. H., Jeon, Y. H., Kim, S. G. and Kim, Y. H. 2007. First report on bacterial soft rot of graft-cactus Chamaecereus silvestrii caused by Pectobacterium carotovorum subsp. carotovorum in Korea. Plant Pathol. J. 23:314-317.

Kim, S. G., Kim, Y. H., Kim, H. T. and Kim, Y. H. 2008. Effect of delayed inoculation after wounding on the development of anthracnose disease caused by Colletotrichum acutatum on chili pepper fruit. Plant Pathol. J. 24:392-399.

Kim, S. G., Jang, Y., Kim, H. Y., Koh, Y. J. and Kim, Y. H. 2010. Comparison of microbial fungicides in antagonistic activities related to the biological control of phytophthora blight in chili pepper caused by Phytophthora capsici. Plant Pathol. J. 26:340-345.

Kim, W. G., Cho, W. D., Jee, H. J. and Hong, S. Y. 2000a. Occurrence of anthracnose on Indian fig cactus caused by Glomerella cingulata and Colletotrichum gloeosporioides. Plant Pathol. J. 16:294-296.

Kim, Y. H., Jun, O. K., Sung, M. J., Shin, J.-S., Kim, J. H. and Jeoung, M.-I. 2000b. Occurrence of colletotrichum stem rot caused by Glomerella cingulata on grafted-cactus in Korea. Plant Pathol. J. 16:242-245.

Köhl, J. and Fokkema, N. J. 1998. Strategies for biological control of necrotrophic fungal foliar pathogens. In: Plant-Microbe Interactions and Biological Control, ed. by G. J. Boland and L. D. Kuykendall, pp. 49-88. Marcel Dekker, Inc., New York.

Lee, S. K., Sohn, H. B., Kim, G. G. and Chung, Y. R. 2006. Enhancement of biological control of Botrytis cinerea on cucumber by foliar sprays and bed potting mixes of Trichoderma harzianum YC459 and its application on tomato in the greenhouse. Plant Pathol. J. 22:283-288.

Liou, M. R., Hung, C. L. and Liou, R. F. 2001. First report of Cactus virus $X$ on Hylocereus undaus (Cactaceae) in Taiwan. Plant Dis. 85:229.

Min, B. E., Chung, B. N., Kim, M. J., Ha, J. H., Lee, B. Y. and Ryu, K. H. 2006. Cactus mild mottle virus is a new cactusinfecting tobamovirus. Arch. Virol. 151:13-21.

Solemani, M. J., Shamsbakhsh, M., Taghavi, M. and Kazemi, Sh. 2005. Biological control of stem and root-rot of wheat caused by Bipolaris spp. by using antagonistic bacteria, fluorescent Pseudomonas and Bacillus spp. J. Biol. Sci. 5:347-353.

Song, C. Y., Ahn, D. H., Cho, C. H., Chung, J. W. and Nam, S. Y. 2009a. Exporting promotion strategy of grafted cacti. Flower Res. J. 17:67-73.

Song, C. Y., Ahn, D. H., Kim, Y. S., Park, I. T. and Cho, C. H. 2009b. Export market trends of grafted cacti. Flower Res. J. 17:62-66.

Walker, R., Powell, A. A. and Seddon, B. 1998. Bacillus isolates from the spermosphere of peas and dwarf French beans with antifungal activity against Botrytis cinerea and Pythium species. J. Appl. Microbiol. 84:791-801.

Weisburg, W., Barns, S. M., Pelletier, D. A. and Lane, D. J. 1991. $16 \mathrm{~S}$ ribosomal DNA amplification for phylogenetic study. $J$. Bacteriol. 173:697-703. 